A. Yousefir ${ }^{1}$, S. Nasehi ${ }^{1}$, S. Arshi' ${ }^{2}$, M. Nabavi², M. H. Bemanian ${ }^{2}$, S. Shokri ${ }^{2}$, F. Seif ${ }^{3}$, M. Khoshmirsafa ${ }^{2}$, Y. SAeEdi ${ }^{2}$, M. SAdeghian ${ }^{5}$, E. Talachian ${ }^{6}$, B. Rajabian ${ }^{4}$, F. Mahjoub $^{7}$, M. FALlahPOUR ${ }^{2}$

\title{
Assessment of IgE- and cell-mediated immunity in pediatric patients with eosinophilic esophagitis
}

\author{
${ }^{1}$ Department of Pediatric Gastroenterology, Rasool e Akram Hospital, Iran University of Medical Sciences, Tehran, Iran \\ ${ }^{2}$ Department of Allergy and Clinical Immunology, Rasool e Akram Hospital, Iran University of Medical Sciences, \\ Tehran, Iran \\ ${ }^{3}$ Department of Immunology and Allergy, Academic Center for Education, Culture, and Research (ACECR), Tehran, Iran \\ ${ }^{4}$ Department of Clinical Pathology, Atieh Hospital, Tehran, Iran \\ ${ }_{5}^{5}$ Department of Pediatric Gastroenterology, Children Medical Center, Tehran University of Medical Sciences, Tehran, Iran \\ ${ }^{6}$ Division of Pediatric Gastroenterology, Ali-Asghar Children's Hospital, Iran University of Medical Sciences, Tehran, Iran \\ ${ }^{7}$ Bahrami Children Hospital, Tehran University of Medical Sciences, Roshan Azma Pathobiology Laboratory, Pediatric \\ Gastro- Enterology Research Center, Tehran, Iran
}

\section{KEY WORDS}

Eosinophilic esophagitis; skin prick test; prick to prick test; atopic patch test; IgE; non-IgE-mediated food allergy.

\section{Corresponding author}

Morteza Fallahpour

Department of Allergy and

Clinical Immunology

Rasool e Akram Hospital

Iran University of Medical Sciences

Niayesh Street, Satarkhan Avenue

Tehran 1449614535, Islamic Republic of Iran

E-mail: fallahpour.m@iums.ac.ir

Doi

10.23822/EurAnnACI.1764-1489.154

\begin{abstract}
Summary
Eosinophilic esophagitis (EoE) is a chronic allergen/immune-mediated disease leading to esophageal dysfunction. Food allergens play critical roles in the pathogenesis and treatment of EoE via different mechanisms. This study aimed to present the characteristics and evaluate the ability of skin prick test (SPT), skin prick to prick test (SPP) (IgE-mediated), and atopic patch test (APT) (cell-mediated) individually or simultaneously to diagnose food allergy in patients suffering from EoE. This prospective study was conducted on 58 patients with EoE. Seven patients (12.1\%) were positive to only one, 3 (5.2\%) were simultaneously positive to two, and $32(55.2 \%)$ were simultaneously positive to three tests. Single and double sensitizations were totally $10.4 \%$ in IgE-mediated reactions, while $36.5 \%$ in cell-mediated reactions. In contrast, poly sensitization (> 2 allergens) was $51.7 \%$ in IgE-mediated tests and $20.7 \%$ in the cell-mediated test. Multiple sensitization findings showed egg white, milk, yolk, and soy were the most frequent allergens. Our findings indicate that EoE is early onset and associated with multiple food sensitizations, particularly via IgE-mediated mechanisms. These immune-mediated responses encompass both IgE-mediated (SPT and SPP) and cell-mediated (APT) reactions simultaneously not individually. Therefore, employing multiple assays may strengthen the diagnosis of food sensitization.
\end{abstract}

\section{Introduction}

Eosinophilic esophagitis (EoE) is a chronic allergen/immune-mediated disease leading to esophageal dysfunction and is characterized by eosinophil infiltration at least 15 eosinophils per high-power field (HPF), no clinical response to high-dose proton pump inhibitors, and normal $\mathrm{pH}$ of the distal esophagus (1). The incidence of EoE has been increased over the past two decades (2). Nevertheless, the role of allergy-mediated responses, clinical manifestation, and the age of onset of EoE is not fully determined. Foods have always been one of the main culprits in the pathogenesis of the disease $(3,4)$. Dietary therapeutic approaches, including amino acid-based elemental diets, either allergy test-directed elimination diets or non-directed empiric elimination diets resulted in partially clinical and histologic remission and can be implemented as the first-line non-pharmacologic therapies $(5,6)$. Furthermore, the role of cellular immunity in EoE is attributed to Th2 responses; thus, allergic patch 
test (APT) may be used for type IV cell-mediated immunity (7, 8). Although trial six or ten-food elimination diet was initially suggested, it is difficult to be continued because patients are deprived of major nutritional elements (9). Therefore, finding a non-invasive and accurate test sounds necessary to diagnose food trigger(s) in EoE. Various tests, such as SPT and APT, showed different results in children and adult in detecting food allergens (10). Therefore, this study aimed to assess the most relevant clinical information such as the onset age of symptoms and clinical presentations along with SPT, SPP, and APT either individually or simultaneously to diagnose food allergy in patients with EoE.

\section{Materials and methods}

This prospective study was conducted on pediatric patients with EoE referred to the Allergy and Pediatric Gastroenterology Outpatient Clinic of three tertiary Hospitals (including Rasoul Akram, Ali Asghar, and Firooz Abadi Hospitals, Tehran, Iran) from September 2013 to January 2018. The EoE disease was confirmed based on 2011 consensus document (11). Written informed consent was obtained from all participants and the study protocol was approved by the Ethics Committee of Iran University of Medical Sciences (IR.IUMS.REC1396.8923496039). The SPT and SPP tests were used for IgE-mediated reactions, while APT was used for cell-mediated reactions (12-14) Statistical analyses were performed using SPSS version 23.0 (Chicago, Illinois, USA). A p-value of less than 0.05 was considered statistically significant.

\section{Results}

Demographic data and clinical manifestation are shown in table I. Of the 58 patients with EOE, 37 (64\%) were males and $21(36 \%)$ were females, the male/female ratio was $1.8: 1$. The median (IQR) gap between symptom onset and the definite diagnosis was 15 (9.37-21.4) months. The five most common clinical manifestations consisted of anorexia (77.6\%), vomiting (69\%), abdominal pain (63.8\%), nausea (56.9\%), and sleep disorder $(37.9 \%)$. The mean age $\pm \mathrm{SD}$ at the first endoscopy was $24.4 \pm 12.2$ months (11 to 60 months). Thirty-one (53.4\%) patients were diagnosed at the first endoscopy, $21(36.2 \%)$ at the second time, 5 patients $(8.6 \%)$ at the third time, and one patient $(1.7 \%)$ after the fourth endoscopy.

Sixteen patients were negative to all of the skin tests and 42 were reactive to at least one of the allergens in three types of the skin tests. Seven patients (12.1\%) were positive to only one kind of skin test, $3(5.2 \%)$ patients were simultaneously positive to two skin tests, and $32(55.2 \%)$ patients were simultaneously positive to the three skin tests. The number of patients with multiple sensitizations (reactive to more than two allergens) in IgE-mediated reactions was $30(51.7 \%)$ cases, whereas in cell-mediated reactions was $12(20.7 \%)$ cases (table II). The most frequent food allergen detected by IgE-mediated tests (SPT and SPP) was cow's milk protein $(46.6 \%)$ and the most frequent detected by APT was egg white (34.5\%). Moreover, the SPT and SPP results revealed that the cow's milk, egg white and yolk (more than ten cases), and soy were the most frequent allergens, while APT indicated egg white, cow's milk, and soy. According to the multiple sensitization results, egg white, milk, yolk, and soy were the most frequent allergens. The lowest positive reactions to food allergens in IgE- and cell-mediated reactions were observed for almond (table III). Twelve (20.7\%) patients were sensitized to yolk in IgE-mediated reactions, but there are only $3(5.2 \%)$ cases in cell-mediated reactions. Multiple sensitizations were more frequent in comparison to single or double sensitizations. Moreover, there was a significant positive correlation between total $\operatorname{IgE}$ and both peripheral eosinophil count $/ \mathrm{mm}^{3}(\mathrm{p}=0.03, \mathrm{r}$ $=0.28)$ and biopsy eosinophil count $/ \mathrm{HPF}(\mathrm{p}<0.001, \mathrm{r}=0.53)$. However, no significant correlation was found between biopsy and peripheral eosinophil counts $(\mathrm{p}=0.53)$.

\section{Discussion}

Skin prick test (SPT or SPP), serum specific IgE assay and APT are the most available allergy tests; however, the specificity and sensitivity of these tests are under investigation (15-17). In parallel with the review of these tests, what is highlighted in our study is the nature of multiple sensitization in this disease, and interestingly, this finding is more evident in the IgE-dependent mechanism than in the cell-dependent mechanism, which $51.7 \%$ of the skin tests in IgE-mediated reactions are multiple sensitizations (more than two allergens), while $20.7 \%$ of the skin tests in the cell-mediated reactions are multiple sensitizations. On the other hand, there were three cases with single sensitization (5.2\%) in IgE-mediated reactions, whereas single sensitization constituted $19 \%$ of cell-mediated reactions. Nevertheless, few studies have been done in this area of research. In the present study, the cow's milk, egg white, yolk, and soy were the most frequent food allergens in IgE-mediate skin tests. In contrast, egg white, cow's milk, rice, and soy were the most frequent food allergens in cell-mediated reactions. Given the frequency of multiple sensitizations, egg, milk, and soy were the most prevalent allergens. Mono and multiple sensitizations in allergy tests are topics that we focused on in the current study, otherwise many studies have performed different allergy tests regardless of this issue; for example, Spergel et al. (7) showed nearly $70 \%$ of the patients were reactive to only 1 to 3 foods. The number of food allergies was consistent with Kagalwalla $e t$ al. cohort study that $72 \%$ of the population was only allergic to one food. Also, they reported that milk, egg, wheat, and soy were the most common food allergens (18). In agreement with the above-mentioned studies, the current study demonstrated that milk, egg, and soy were the most prevalent food allergen. 
Table I - Demographic characteristics and clinical data of the patients with EOE.

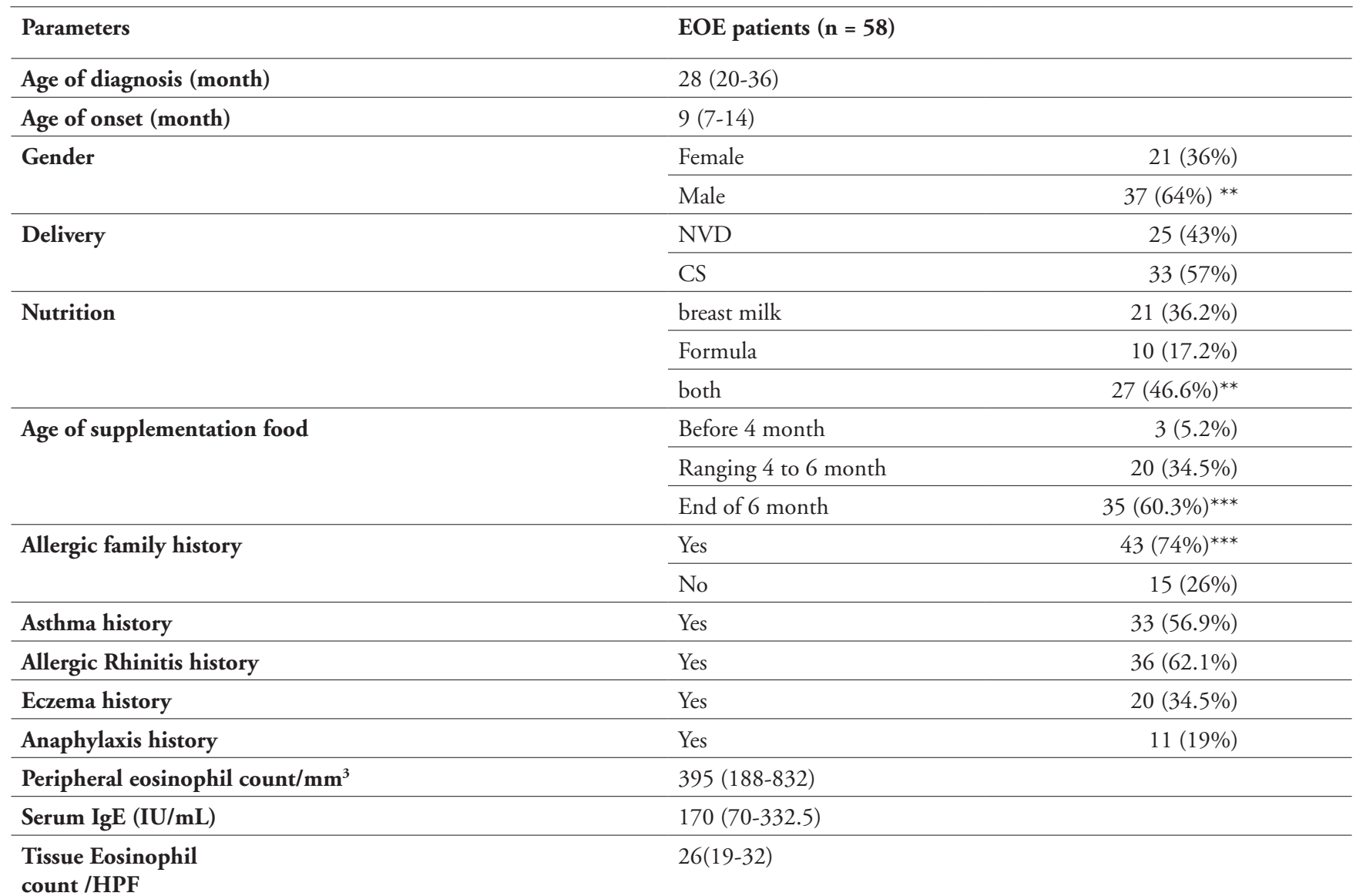

Cesarean Section (CS).

Normal Vaginal Delivery (NVD).

Data were presented as median (IQR) and frequency (\%).

Using one-sample chi-square test the p-value $<0.01$ and $<0.001$ presented as ${ }^{* *}$ and ${ }^{* * *}$, respectively.

Table II - The results range from single sensitization to multiple sensitizations.

\begin{tabular}{lllll}
\hline Skin test & $\begin{array}{l}\text { Single } \\
\text { sensitization }\end{array}$ & $\begin{array}{l}\text { Double } \\
\text { sensitizations }\end{array}$ & $\begin{array}{l}\text { Multiple } \\
\text { sensitizations }\end{array}$ & $\begin{array}{l}\text { Totally: } \\
\text { Negative vs. Positive }\end{array}$ \\
\hline IgE-mediated (\%) & 3 & 3 & 30 & $22(37.9)$ \\
& $(5.2)$ & $(5.2)$ & $(51.7)^{* * *}$ & $36(62.1)^{* *}$ \\
\hline Cell-Mediated (\%) & 11 & 9 & 12 & $26(44.8)$ \\
& $(19)$ & $(15.5)$ & $(20.7)$ & $32(55.2)$ \\
\hline IgE- and cell-mediated (\%) & 7 & 3 & $32(55.2)^{* * *}$ & $16(27.6)$ \\
& $(12.1)$ & $(5.2)$ & & $42(72.4)^{* *}$ \\
\hline
\end{tabular}

The $\mathrm{p}$-value $<0.01$ and $<0.001$ presented as ${ }^{* *}$ and ${ }^{* * *}$, respectively. 
Table III - The frequency of allergens based on types of skin tests.

\begin{tabular}{|c|c|c|c|c|c|c|c|}
\hline \multirow[t]{5}{*}{ Allergens } & \multicolumn{7}{|c|}{ Skin Tests } \\
\hline & \multicolumn{2}{|c|}{ IgE-mediated } & \multirow{2}{*}{$\frac{\text { Cell-mediated }}{\wedge \mathrm{APT}}$} & \multicolumn{4}{|c|}{$\wedge \wedge \mathrm{SPT}+\mathrm{SPP}+\mathrm{APT}$} \\
\hline & $\wedge$ SPT & $\wedge \mathrm{SPP}$ & & & & & \\
\hline & \multirow{2}{*}{$\begin{array}{l}\text { Positive } \\
\text { (\%) }\end{array}$} & \multirow{2}{*}{$\begin{array}{c}\text { Positive } \\
\text { (\%) }\end{array}$} & \multirow{2}{*}{$\begin{array}{c}\text { Positive } \\
\text { (\%) }\end{array}$} & \multirow{2}{*}{$\begin{array}{c}\text { Negative } \\
(\%)\end{array}$} & \multicolumn{3}{|c|}{ Positive $(\%) \dagger$} \\
\hline & & & & & Single Allergen & Double Allergens ${ }^{\dagger}$ & Multiple Allergens $\dagger_{\dagger}$ \\
\hline Milk & $22(37.9)$ & $27(46.6)$ & $13(22.4)$ & $29(50)$ & $1(1.7)$ & $2(3.4)$ & $26(44.1)^{* *}$ \\
\hline Egg white & $19(32.8)$ & $23(39.7)$ & $20(34.5)$ & $28(48.3)$ & $1(1.7)$ & $2(3.4)$ & $28(47.5)^{* *}$ \\
\hline Yolk & $12(20.7)$ & $12(20.7)$ & $3(5.2)$ & $38(65.6)$ & $1(1.7)$ & $1(1.7)$ & $18(30.5)^{* *}$ \\
\hline Soya & $11(19)$ & $12(20.7)$ & $8(13.8)$ & $40(70)$ & $2(3.4)$ & $1(1.7)$ & $16(27.6)^{* *}$ \\
\hline Wheat & $8(13.8)$ & $3(5.2)$ & $4(6.9)$ & $50(86.2)$ & $1(1.7)$ & 0 & $7(12.1)$ \\
\hline Meat & $6(10.3)$ & $3(5.2)$ & $2(3.4)$ & $51(87.9)$ & $1(1.7)$ & 0 & $7(12.1)$ \\
\hline Peanut & $6(10.3)$ & $5(8.6)$ & $5(8.6)$ & $45(77.6)$ & $1(1.7)$ & $1(1.7)$ & $10(17.2)^{* *}$ \\
\hline Fish & $4(6.9)$ & $1(1.7)$ & $1(1.7)$ & $53(91.4)$ & 0 & 0 & $5(8.6)$ \\
\hline Rice & $4(6.9)$ & $4(6.9)$ & $9(15.5)$ & $47(81)$ & 0 & 0 & $11(19)$ \\
\hline Chicken & $3(5.2)$ & $1(1.7)$ & $1(1.7)$ & $55(94.8)$ & 0 & 0 & $3(5.2)$ \\
\hline Sesame & $3(5.2)$ & $5(8.6)$ & $5(8.6)$ & $49(84.5)$ & 0 & 0 & $9(15.5)$ \\
\hline Almond & $2(3.4)$ & $1(1.7)$ & $0(0)$ & $56(96.6)$ & 0 & 0 & $2(3.4)$ \\
\hline
\end{tabular}

$\wedge$ Each test is assessed alone. $\wedge \wedge$ tests are assessed simultaneously.

$\dagger$ The positive results for three skin tests were considered totally for different food allergens.

$\dagger \dagger$ Double allergens were considered when that allergen was positive with another food at the same time in one kind of tests.

$\dagger \dagger$ Multiple Allergens were considered when that allergen was positive with more than 2 foods at the same time in one kind of test.The $\mathrm{p}$-value $<0.01$ and $<0.001$ presented as $^{* *}$ and ${ }^{* * *}$, respectively.

Finding the exact food allergen as a true trigger is the main challenging topic in these dietary therapies. Most studies have shown that the use of different methods can increase the chance of success in identifying allergens. However, there are some problems regarding this attitude; for example, basophil activation test is not available everywhere and APT is not well-standardized for implementation or interpretation $(19,20)$. Consistent with these studies, Philpott $e$ al . declared that SPT, APT, sIgE, and BAT could not predict the exact food sensitivity related to EoE in comparison to oral food challenge as a gold standard test. We demonstrated that multiple assays can simultaneously increase the chance of finding positive sensitization results and may help find true trigger(s) to manage appropriate dietary therapy. But there are still two major challenges: first, these findings can only represent sensitization, not the main culprit and second, several studies previously established that local specific IgE production may play an important role in the pathogenesis of $\operatorname{EoE}(21,22)$ and these tests miss the local $\mathrm{IgE}$ production. Gottlieb et al. (23) concluded that directed dietary elimination and reintroduction based on SPT/APT is not a worthwhile treatment approach, while other studies $(24,25)$ suggested that diet modification based on SPT/APT is a valuable approach in patients with EoE. On the other hand, the most limitation of the test-guided approach is its inability to detect true allergens. We discussed that this study along with other available evidence suggests that the combination of different tests may increase the success rate for food allergen detection and another important finding is the nature of polysensitization in the pathogenesis of EoE, especially in IgE-mediated mechanism.

Our findings revealed that EOE is early onset and associated with multiple sensitizations to common food allergens. Although both IgE- and cell-mediated mechanisms are suggested in the pathogenesis, it appears that their impact and role in the pathogenesis are different and they may be helpful to categorize patients into IgE- or cell-mediated groups; accordingly, therapeutic approaches may be different. The mixed IgE- and cell-mediated nature of 
this disease necessitates the use of different laboratory methods that may elucidate different mechanisms.

\section{Fundings}

Neither financial support nor a grant was received for this study.

\section{Conflict of interests}

The authors declare they have no conflict of interests.

\section{References}

1. Dellon ES, Gonsalves N, Hirano I, Furuta GT, Liacouras CA, Katzka DA; American College of Gastroenterology. ACG clinical guideline: Evidenced based approach to the diagnosis and management of esophageal eosinophilia and eosinophilic esophagitis (EoE). Am J Gastroenterol 2013;108(5):679-92; quiz 693.

2. Jensen ET, Kappelman MD, Martin CF, Dellon ES. Healthcare utilization, costs, and the burden of disease related to eosinophilic esophagitis in the United States. Am J Gastroenterol 2015;110(5):626-32.

3. Mishra A, Hogan SP, Brandt EB, Rothenberg ME. An etiological role for aeroallergens and eosinophils in experimental esophagitis. J Clin Invest 2001;107(1):83-90.

4. Akei HS, Mishra A, Blanchard C, Rothenberg ME. Epicutaneous antigen exposure primes for experimental eosinophilic esophagitis in mice. Gastroenterology 2005;129(3):985-94.

5. Arias A, González-Cervera J, Tenias JM, Lucendo AJ. Efficacy of dietary interventions for inducing histologic remission in patients with eosinophilic esophagitis: a systematic review and meta-analysis. Gastroenterology 2014;146(7):1639-48.

6. Reed CC, Fan C, Koutlas NT, Shaheen NJ, Dellon ES. Food elimination diets are effective for long-term treatment of adults with eosinophilic oesophagitis. Aliment Pharmacol Ther 2017;46(9):836-844.

7. Spergel JM, Brown-Whitehorn TF, Cianferoni A, et al. Identification of causative foods in children with eosinophilic esophagitis treated with an elimination diet. J Allergy Clin Immunol 2012;130(2):461-7.e5.

8. Rothenberg ME. Biology and treatment of eosinophilic esophagitis. Gastroenterology 2009;137(4):1238-49.

9. Cotton CC, Eluri S, Wolf WA, Dellon ES. Six-Food Elimination Diet and Topical Steroids are Effective for Eosinophilic Esophagitis: A Meta-Regression. Dig Dis Sci 2017;62(9):2408-2420.

10. Molina-Infante J, Martin-Noguerol E, Alvarado-Arenas M, Porcel-Carreño SL, Jimenez-Timon S, Hernandez-Arbeiza FJ. Selective elimination diet based on skin testing has suboptimal efficacy for adult eosinophilic esophagitis. J Allergy Clin Immunol 2012;130(5):1200-2.
11. Liacouras CA, Furuta GT, Hirano I, et al. Eosinophilic esophagitis: updated consensus recommendations for children and adults. J Allergy Clin Immunol 2011;128(1):3-20.e6; quiz 21-2.

12. Duarte I, Lazzarini R, Buense R. Interference of the position of substances in an epicutaneous patch test battery with the occurrence of false-positive results. Am J Contact Dermat 2002;13(3):125-32.

13. Rekabi M, Arshi S, Bemanian MH, et al. Evaluation of a new protocol for wheat desensitization in patients with wheat-induced anaphylaxis. Immunotherapy 2017;9(8):637-645.

14. Salari F, Bemanian MH, Fallahpour M, et al. Comparison of Diagnostic Tests with Oral Food Challenge in a Clinical Trial for Adult Patients with Sesame Anaphylaxis. Iran J Allergy Asthma Immunol 2020;19(1):27-34.

15. Anyane-Yeboa A, Wang W, Kavitt RT. The Role of Allergy Testing in Eosinophilic Esophagitis. Gastroenterol Hepatol (N Y) 2018;14(8):463-469.

16. Ballmer-Weber BK. Value of allergy tests for the diagnosis of food allergy. Dig Dis 2014;32(1-2):84-8.

17. Aceves SS. Food allergy testing in eosinophilic esophagitis: what the gastroenterologist needs to know. Clin Gastroenterol Hepatol 2014;12(8):1216-23.

18. Kagalwalla AF, Shah A, Li BU, et al. Identification of specific foods responsible for inflammation in children with eosinophilic esophagitis successfully treated with empiric elimination diet. J Pediatr Gastroenterol Nutr 2011;53(2):145-9.

19. Gonsalves N, Yang GY, Doerfler B, Ritz S, Ditto AM, Hirano I. Elimination diet effectively treats eosinophilic esophagitis in adults; food reintroduction identifies causative factors. Gastroenterology 2012;142(7):1451-9.e1; quiz e14-5.

20. Philpott H, Nandurkar S, Royce SG, Thien F, Gibson PR. Allergy tests do not predict food triggers in adult patients with eosinophilic oesophagitis. A comprehensive prospective study using five modalities. Aliment Pharmacol Ther 2016;44(3):223-33.

21. Hsu Blatman KS, Gonsalves N, Hirano I, Bryce PJ. Expression of mast cell-associated genes is upregulated in adult eosinophilic esophagitis and responds to steroid or dietary therapy. J Allergy Clin Immunol 2011;127(5):1307-8.e3.

22. Vicario M, Blanchard C, Stringer KF, et al. Local B cells and IgE production in the oesophageal mucosa in eosinophilic oesophagitis. Gut 2010;59(1):12-20.

23. Gottlieb SJ, Johnston DT, Markowitz JE. A role for food allergy testing in eosinophilic esophagitis. J Allergy Clin Immunol 2013;131(1):242-3.

24. Spergel JM, Beausoleil JL, Mascarenhas M, Liacouras CA. The use of skin prick tests and patch tests to identify causative foods in eosinophilic esophagitis. J Allergy Clin Immunol 2002;109(2):363-8.

25. Spergel JM, Andrews T, Brown-Whitehorn TF, Beausoleil JL, Liacouras CA. Treatment of eosinophilic esophagitis with specific food elimination diet directed by a combination of skin prick and patch tests. Ann Allergy Asthma Immunol 2005;95(4):336-43. 